\title{
Research of Span Ratio of Non-abutment Slant-legged Rigid Frame Bridge
}

\author{
Xue-shen Dong ${ }^{1, a^{*}}$, Xiao-jun Ning ${ }^{1, b}$ \\ ${ }^{1}$ Faculty of Civil Engineering and Mechanics,Kunming University of Science and \\ Technology,Kunming,China

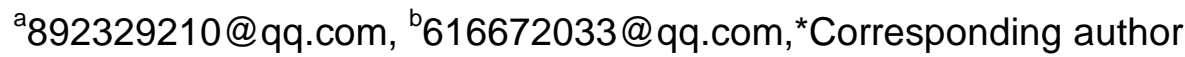

\begin{abstract}
Keywords: Non-abutment slant-legged rigid frame brige;Span ratio;Internal force
Abstract:This paper mainly makes the research of the influence on internal force and displacement of non-abutment slant-legged rigid frame brige by different span ratio. The results of the research indicate that as the change of span ratio,the internal force and displacement of each control section of brige structure have different change. We can find the change rule by summaring and comparing the different change,so this paper will provide reference for the design and construction of non-abutment slant-legged rigid frame brige.
\end{abstract}

\section{Introduction}

Non-abutment slant-legged rigid frame brige has the double characteristics and advantages on struture force which the beam and arch have,presenting a good mechanics performance[1].The actual project prove that the mechanics performance, economic advantages and aesthetic value make non-abutment slant-legged rigid frame brige become a very competitive bridge in overpass bridges and single-span across the river bridges.In order to provide the reliable basis for the design of this kind of bridge,it is necessary to study this structual features and demonstration analysis.In the design of non-abutment slant-legged rigid frame brige,different span ratio $\mathrm{L}_{1}: \mathrm{L}_{2}$ will lead to different section internal force .In this article,through the calculation of the finite element program-Midas/Civil,under the effect of constant load,achieve the changing rule of the displacement and stress of bridge structure with the change of structure span ratio.

\section{Introduction of the Engineering background}

Nong-Ke South road bridge, the main hole span is $33 \mathrm{~m}$, design reference period is 100 years,load level is A level for the city.The upper structure is variable cross-section slant-legged rigid frame brige,the oblique angle is 15 degrees. The full width of bridge is $25 \mathrm{~m}$, which is consisted by two $12.5 \mathrm{~m}$-wide variable cross-section beam body, section slab width of each beam is $9 \mathrm{~m}$, the wing width is $1.75 \mathrm{~m}$.A single beam body is single box double chamber section, the thickness of edge web and middle web is 0.5 $m$, the height of centre across beam is $1.2 \mathrm{~m}$, the height of beam at the slant-leg support place is $1.8 \mathrm{~m}$, the height of beam at side span fulcrum place is $1.4 \mathrm{~m}$, the thickness of the beam roof is $0.25 \mathrm{~m}$, the thickness of the plate is from $0.25 \mathrm{~m}$ at midspan to $0.45 \mathrm{~m}$ at across fulcrum. The change curve of main girder beam height from midspan to across fulcrum is $y=0.0025558 x^{2}+1.2(m)$, the change curve of the thickness of the plate is $y=0.000852 x^{2}+0.25(\mathrm{~m})$, the section of slant-leg is $1.2 \mathrm{~m}$ width rectangle. The horizontal tilt angle of edge diagonal rod is $55.43^{\circ}$, The horizontal tilt angle of slant-leg is $45^{\circ}$.

\section{Span optimization analysis}

The distribution of size of span in three span continuous beam bridge is based on the similar negative bending of adjacent span to arrange. One of the advantages to arrange like this is make the beam height and bending at nodes both ends harmonious,so the ratio of midspan length and side span length of general continuous beam is $0.65 \sim 0.8: 1$. 


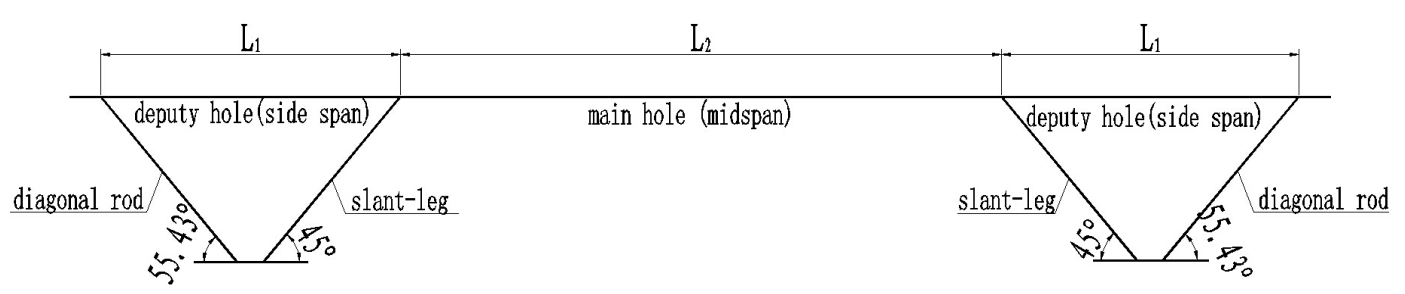

Fig. 1 Structural Representation

q

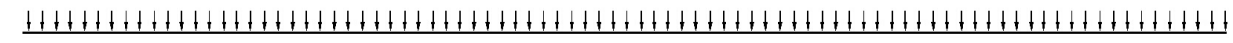

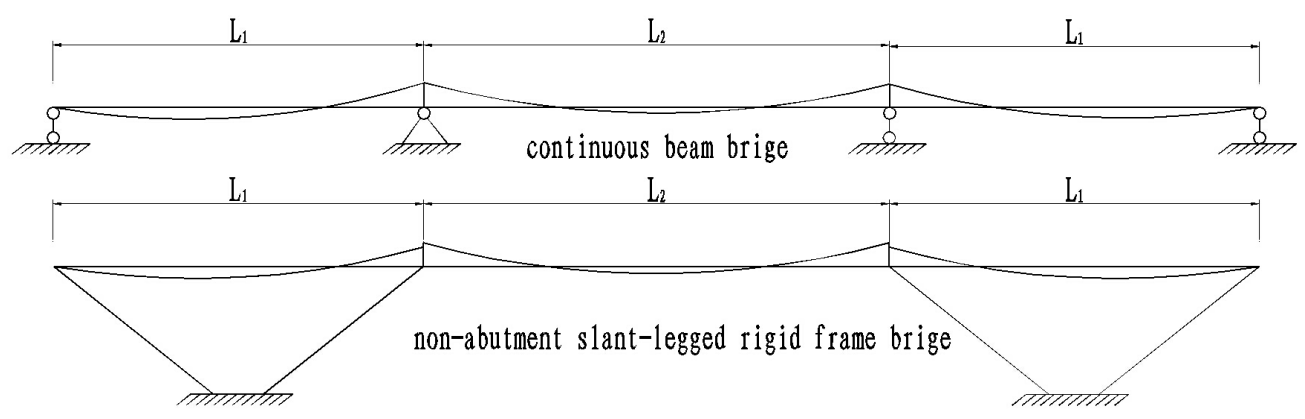

Fig. 2 Contrast of Two Kinds of Bridge

Fig. 2 indicates that two kinds of bridge has similaritiy and difference in stress,namely bending moment distribution of main girder is similar,otherwise on account of effective axial stress in the main hole middle beam of non-abutment slant-legged rigid frame brige, which make main girder from pure bending beam column to compression-bending column,the benefits of this can increace the length of midspan.But because of the existence of side span tensile stress, the beam at side span will cracks easily,so the side span should be reduce.

\section{The assumption of structure analysis}

Bridge design is a process of gradual optimization.In order to understand the different mechnical charateristics of non-abutment slant-legged rigid frame brige at different span ratio and achieve the optimal span ratio,this paper use the finite element program-Midas/Civil to analyze.For the sake of illtstrating comparison is more persuasive in the same conditions, it is necessary to make relevant assumptions when analysing the struture:

1, When the structure is calculating,keep the midspan $\mathrm{L}_{2}=33 \mathrm{~m}$ unchanged, change the side span $\mathrm{L}_{1}$ according to $\mathrm{L}_{1}: \mathrm{L}_{2}=0.3 \sim 0.8: 1$.

2,Being analyzed,structure always stay online within the elastic range.Standard strength of concrete is $C 50$,elasticity modulus is $3.45 \times 10^{4} \mathrm{Mpa}$, concret density is $26 \mathrm{kN} / \mathrm{m}^{3}$, poisson's ratio is 0.2 .

3 ,We only calculate the stress and deformation in the normal use stage, without considering the stress combination in construction stage.

4 , Being analyzed,structure is acted by only constant load, without considerding variabel action or other factors.

5,According to the usually regulations of mechanics of materials,tensile stress is positive, compressive stress is negative.

\section{Analysis of internal force and displacement as the structure's span ratio changes}

The model which this paper use is as the following fig. 3 shown, whose boundary condition is taken rigid coupling into account. 


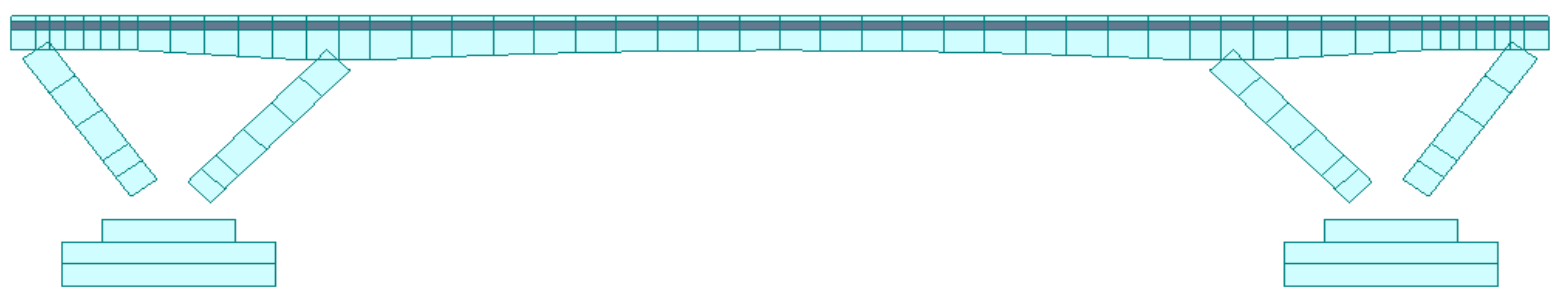

Fig. 3 Model of non-abutment slant-legged rigid frame brige

\section{Comparison of internal force an span ratio change.}

Non-abutment slant-legged rigid frame brige is a high statically indeterminate structure, which is complex, and has more control section. Selecting several key parts to analyze is effective, the weight of structure occupied large proportion.In order to simply the calculation and analysis, the analysis of structure only consider the internal force caused by self-weight action.

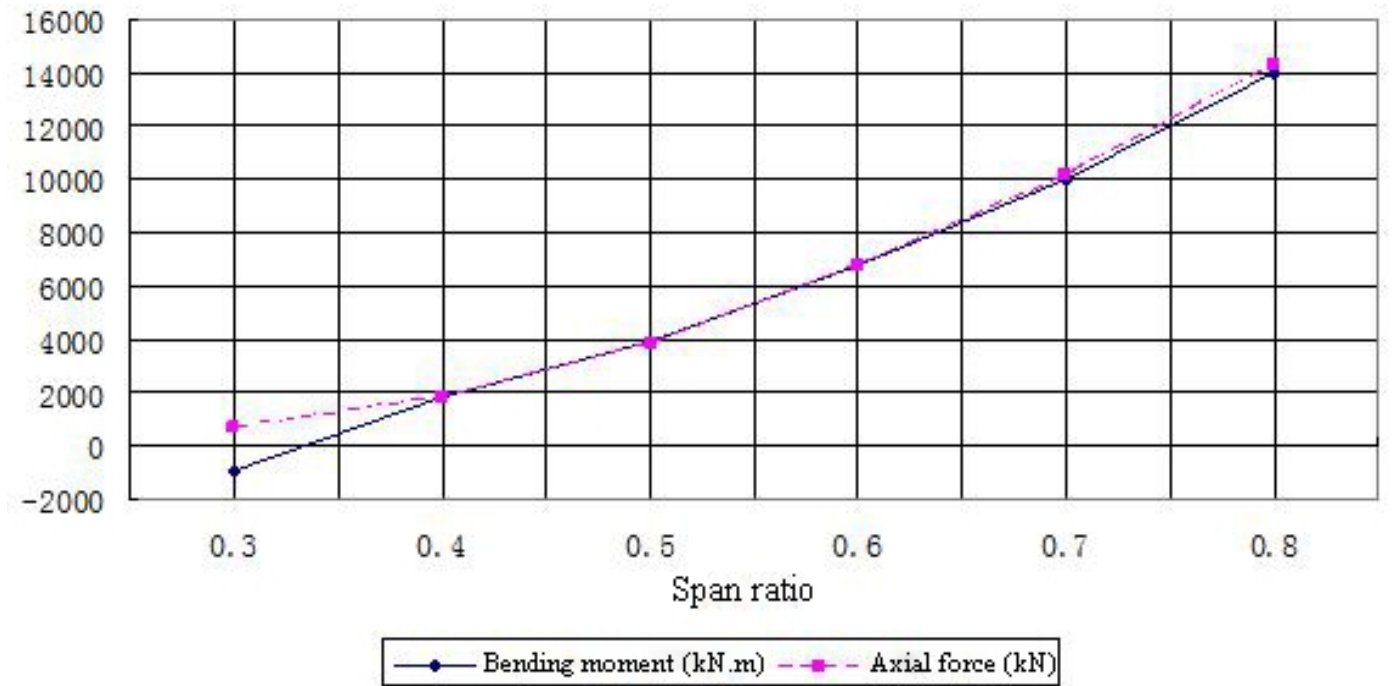

Fig. 4 Structure effect of midspan section of side span

Fig. 4 indicates that the bending moment and axial force of midspan section of side span changes with the span ratio is positive correlation, the axial force is tension force when the side- middle span ratio bigger than 0.33 . When the side- middle span ratio changes in the range of $0.4 \sim 0.6$, the change range of internal force relatively small.If we only consider the section of midspan section of side span,the sidemiddle span ratio in the range of $0.4 \sim 0.6$ is quite reasonable.

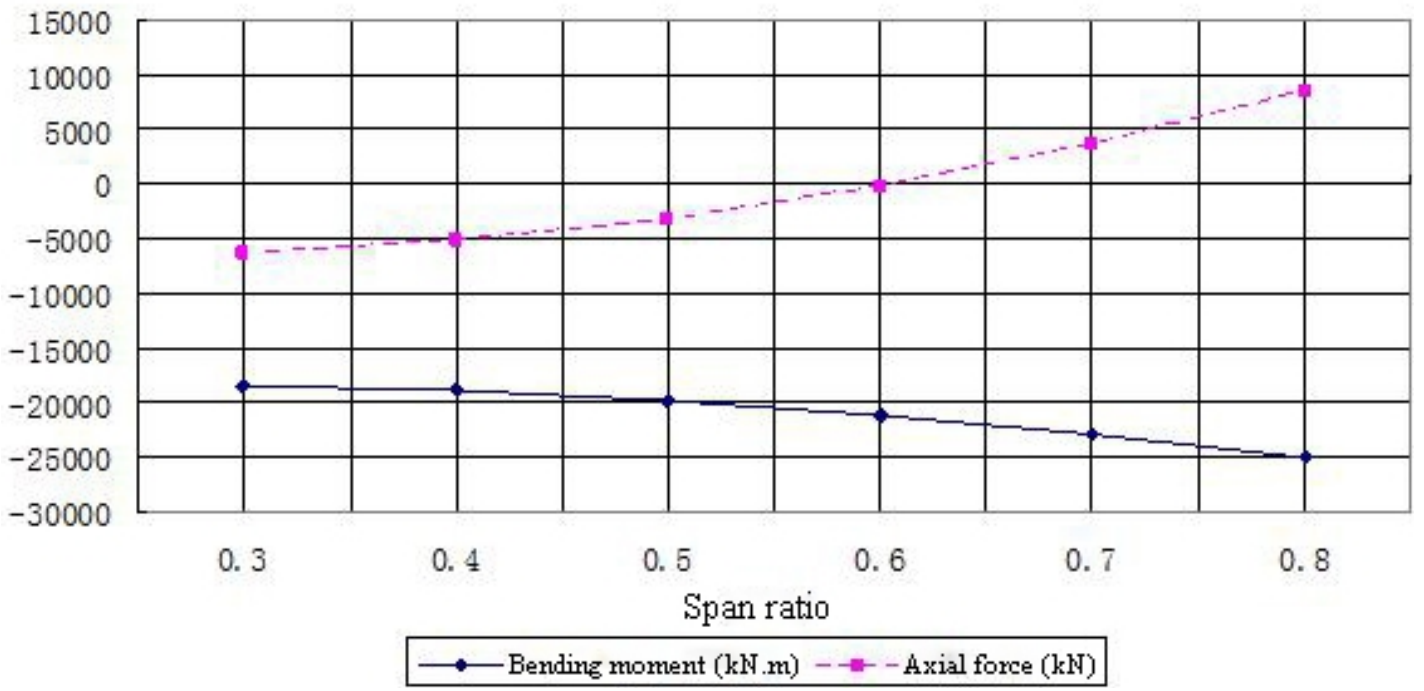

Fig. 5 Structure effect of midspan inner fulcrum section

Fig. 5 indicates that the side- middle span ratio has a certai impact on bending moment of midspan inner fulcrum section, but the effect is not obvious. The influence on axial force by span ratio is 
obvious, as the side- middle span ratio increace, axial force changes from pressure to tension.In terms of bending moment, when the side- middle span ratio in $0.3 \sim 0.6$ range, its change is quite gentle, however axial force is pressure.In conclusion the side- middle span ratio in $0.3 \sim 0.6$ range is reasonable.

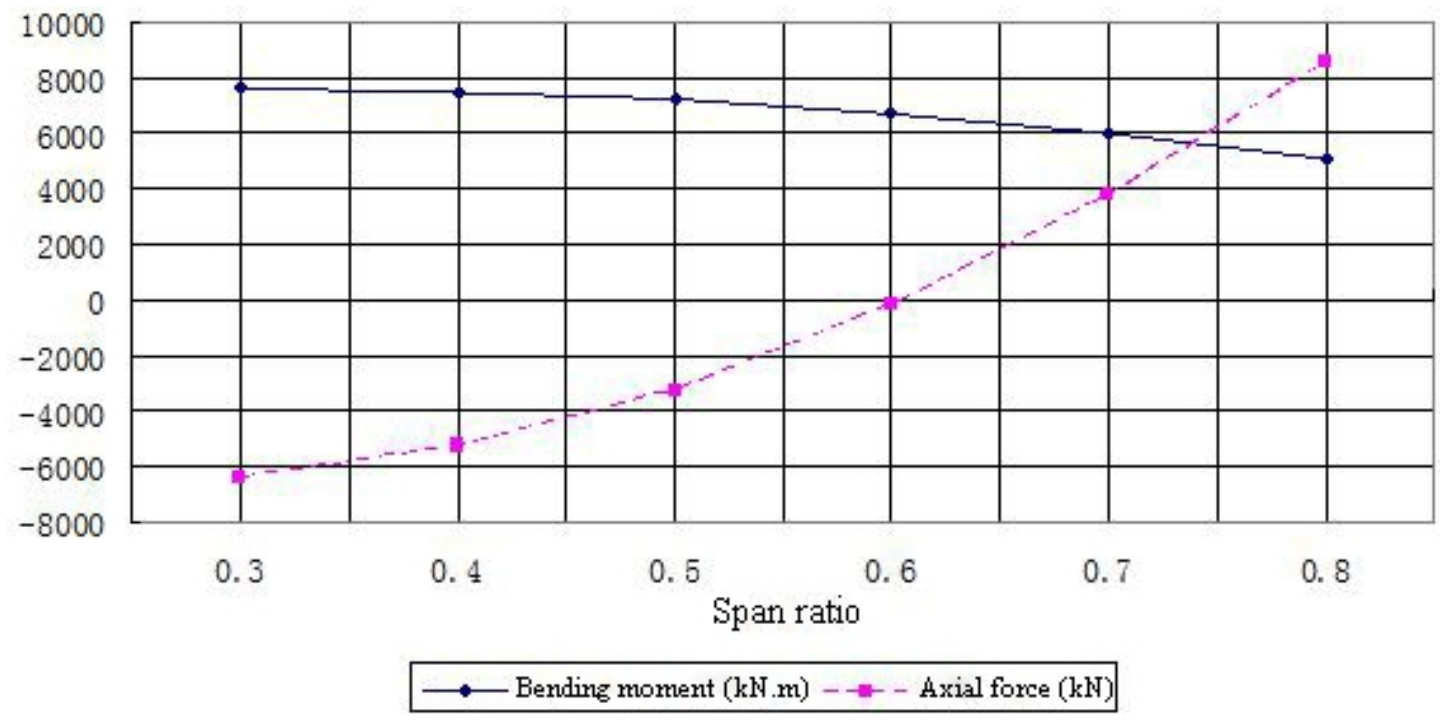

Fig. 6 Structure effect of section in the midspan cross

Fig. 6 indicates that when the side- middle span ratio is over 0.6 ,the axial force of section in the midspan cross performs tension, which is adverse to anti-cracking ability. While bending moment tends to be more small as the side- middle span ratio in $0.3 \sim 0.8$ range.In terms of section in the midspan cross, the side- middle span ratio in $0.3 \sim 0.6$ range is reasonable.

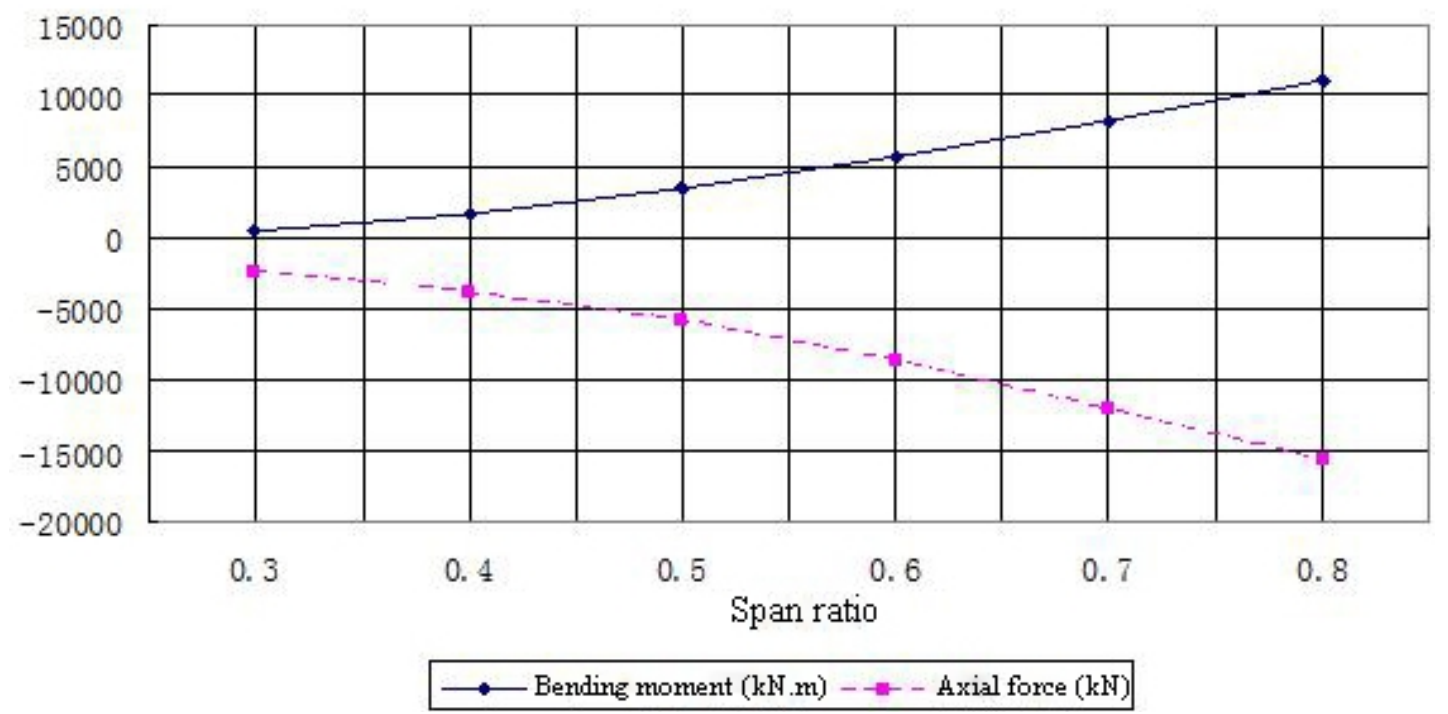

Fig. 7 Structure effect of each section of side diagnal rod

Because the size of side diagnal rod is limited, this paper did not divide to specific section to discuss, but took the member to discuss.In Fig. 6,the maximum bending moment is in the top section of side diagnal rod, otherwise axial force is in the bottom section of side diagnal rod. There is no bounce of plus or minus at the height direction of side diagnal rod.As can be seen from Fig. 6, the side- middle span ratio in $0.3 \sim 0.6$ range is acceptable.

\section{Comparison of displacement effect of structure acted by self-weight.}

In this displacement calculation, this paper only focuses on the vertical displacement of two midspan section,fulcrum of midspan and top section of side diagnal rod.

Fig.7 indicates that displacement change extent of side span midspan section and side diagnal rod top section when the side- middle span ratio in $0.6 \sim 0.8$ range is more big than which in $0.3 \sim 0.6$ 
range. When the side- middle span ratio in $0.3 \sim 0.4$ range, the displacement of section in the midspan cross is more big.In terms of section in the midspan cross, when the side- middle span ratio in $0.4 \sim$ 0.8 ,the displacement control is more reasonable.The side- middle span ratio has little effect on the

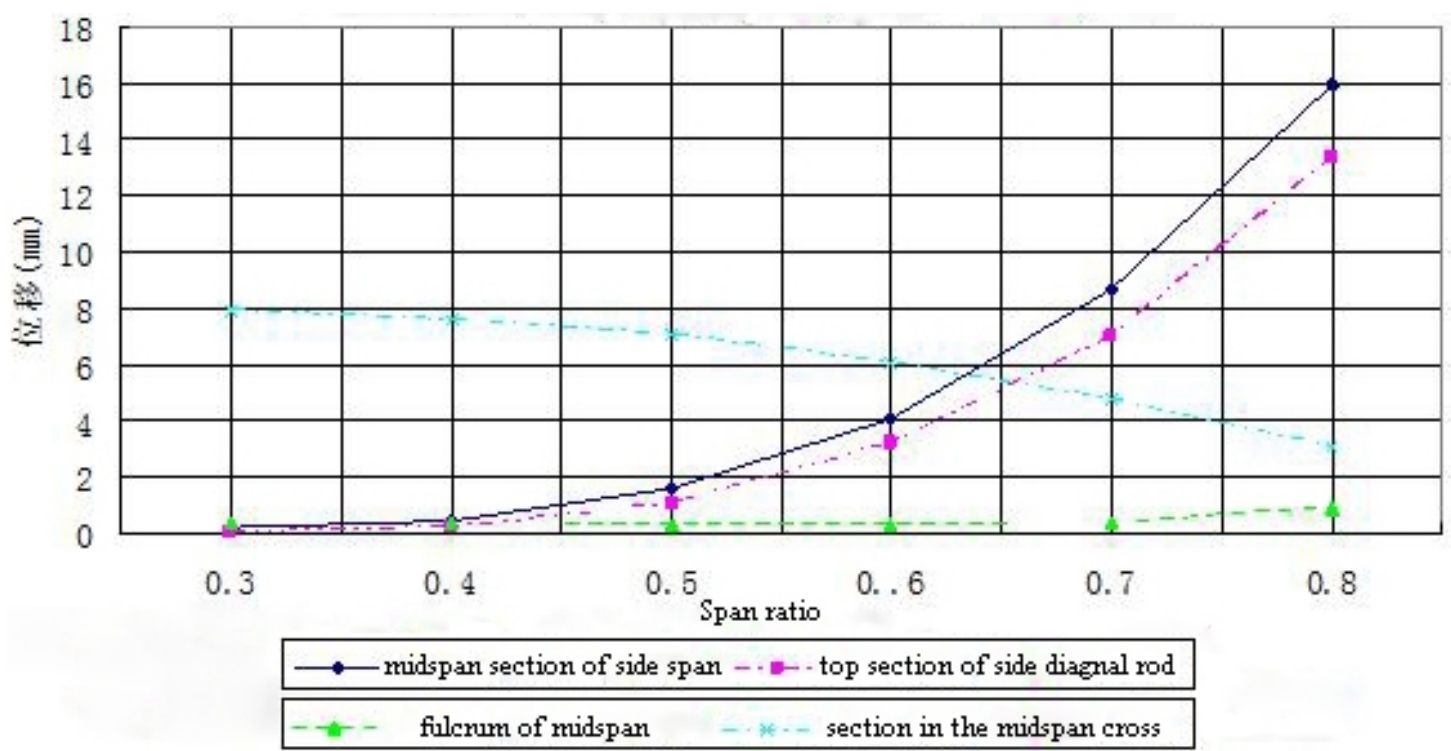

Fig. 8 Displacement effect of member section

displacement of fulcrum midspan. the side- middle span ratio in $0.4 \sim 0.6$ range is reasonable in engineering compromise.

\section{Summary}

In conclusion,adjudting the span ratio of structure can change the distribution of internal force.Dead load occupied a large proportion of the total loads,especially in the long-span bridges,so the laws of internal force caused by dead load have certain representativeness, therefore, the above analysis is based on dead load[2]. Through the bridge internal force and displacement analysis, this paper concluded that the structure acted by self-weight span ratio $L_{1}: L_{2}=0.4 \sim 0.6: 1$ is quite reasonable .

\section{Acknowledgements}

This work was financially supported by the National Science Foundation of China (51068012) and the Yunnan Province Communications Department Science and Technology Program (2013(c)07).

\section{References}

[1] Lai Xia, Discussion of the performance feature,applicability and modelling of the small and medium span slant-legged rigid frame brige[J] . Urban Roads Bridge \&Flood Control .2002.3(1):18-21 [2] Hu Jun,Long-Span Bridge:Theory and Analysis[M].Wuhan:Huazhong University of Science and Technology.2012 